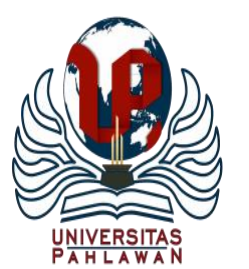

Jurnal Abdidas Volume 2 Nomor 5 Tahun 2021 Halaman 1168-1179

JURNAL ABDIDAS

http://abdidas.org/index.php/abdidas

\title{
Peningkatan Kemampuan Bahasa Inggris bagi Pegawai UPTD Tempat Pengelolaan Sampah Dinas Kehutanan dan Lingkungan Hidup Provinsi Bali
}

\author{
I Wayan Budiarta ${ }^{1}$, Ni Wayan Kasni ${ }^{2}$, Made Susini ${ }^{3}$ \\ Universitas Warmadewa, Indonesia ${ }^{1,2,3}$ \\ E-mail: budy4rt476@gmail.com ${ }^{1}$, wayankasni@gmail.com ${ }^{2}$, susipermana89@gmail.com $^{3}$
}

\begin{abstract}
Abstrak
Pengabdian kepada masyarakat ini bertujuan untuk mengatasi permasalahan karyawan dalam meningkatkan kemampuan berbahasa Inggris mereka. Peningkatan kemampuan berbahasa Inggris sangat dibutuhkan oleh para karyawan karena mereka biasanya dikunjungi oleh orang asing yang ingin mendapatkan informasi tentang kebijakan tentang pengelolaan pembuangan sampah sebagai salah satu masalah Bali sebagai daerah tujuan wisata. Untuk mengatasi masalah peningkatan kemampuan berbicara bahasa Inggris karyawan, diperlukan metode pengajaran bahasa Inggris yang inovatif dan efektif sehingga dapat meningkatkan bahasa Inggris mereka secara signifikan. Metode pengajaran yang diterapkan dalam melakukan pengabdian masyarakat ini adalah Communicative Language Teaching (CLT). Metode ini secara fungsional menekankan bagaimana bahasa digunakan, sedangkan secara struktural, CLT menekankan pada sistem atau aturan bahasa. Pelatihan Bahasa Inggris telah dilakukan dengan menggunakan metode Communicative Language Teaching selama delapan kali pertemuan. Setelah mengikuti pelatihan selama delapan kali, hasil pelatihan menunjukkan adanya peningkatan kemampuan berbicara bahasa Inggris peserta yang awalnya berada pada kisaran 2,55 untuk pretest kemudian meningkat menjadi 4,05 untuk post-test dengan skor kisaran 1-5. Hal ini membuktikan bahwa pelatihan bahasa Inggris yang diberikan kepada peserta telah mampu meningkatkan kemampuan bahasa Inggris mereka secara signifikan.
\end{abstract}

Kata kunci: pelatihan bahasa Inggris, communicative language teaching, kemampuan berbahasa inggris

Abstract

The aim of this community service is to solve the problem of the employees in improving their English speaking ability. The improvement of English speaking ability is highly required by the employees as they were usually visited by foreigners who wanted to get the information about the policy about waste disposal management as one Bali's problem as tourism destination area. To solve the problem of improving the English speaking ability of the employee, innovative and effective teaching method of English are required so it can improve their English significantly. The teaching method applied in conducting this community service is Communicative Language Teaching (CLT). This method Functionally emphasizes how the language is used, while structurally, CLT emphasizes the system or rules of the language. The English training has been conducted by the using of Communicative Language Teaching method for eight meetings. After undertaking the training for eight times, the results of the training showed an increase in the English speaking ability of the participants, which initially was in the range of 2.55 for the pre-test then increase to 4.05 for the post-test with a score range of 1-5. This proves that the English training provided to participants has been able to significantly improve their English language ability.

Keywords: english training, communicative language teaching, english speaking ability

Copyright (c) 2021 I Wayan Budiarta, Ni Wayan Kasni, Made Susini

$\triangle$ Corresponding author

Address : Jl. Terompong No 24 Denpasar Bali

ISSN 2721- 9224 (Media Cetak)

Email : budy4rt476@gmail.com

ISSN 2721- 9216 (Media Online)

DOI : https://doi.org/10.31004/abdidas.v2i5.442 
1169 Peningkatan Kemampuan Bahasa Inggris bagi Pegawai UPTD Tempat Pengelolaan Sampah Dinas Kehutanan dan Lingkungan Hidup Provinsi Bali- I Wayan Budiarta, Ni Wayan Kasni, Made Susini DOI: https://doi.org/10.31004/abdidas.v2i5.442

\section{PENDAHULUAN}

Masa pandemi Covid-19 saat ini yang sudah dirasakan sejak Maret 2020 memang sangat berdampak pada tingkat kunjungan wisatawan ke Bali yang cenderung menurun secara drastis. Hal ini tidak bisa dihindari karena negaranegara yang menyumbangkan wisatawan yang berkunjung ke Indonesia juga mengalami hal yang sama, sehingga negara-negara tersebut membatasi dan bahkan melarang warganya untuk berpergian ke luar negeri untuk menghindari penularan dan juga menghindari penyerbaran virus ini semakin meluas. Kondisi seperti ini tidak boleh membuat kita menyerah untuk tetap berusaha menjaga dan mempertahankan keberlangsungan pariwisata di Bali.

Selain masalah pandemi Covid-19 saat ini, pariwisata Bali juga menghadapi masalah lain yang sudah ada sejak sebelum pandemi Covid -19 ini yang juga mengancam keberlanjutan pariwisata Bali. Bali sebagai salah satu destinasi favorit bagi wisatawan lokal maupun internasional yang sering disebut sebagai sebuah pulau surga yang menawan memiliki permasalahan yang menjadi sisi kelemahan dalam pembangunan dan pengembangan sektor pariwisatanya. Tiga permasalahan utama yang dinventarisasi dalam pengembangan pariwisata di Bali adalah 1) sampah, 2) stabilitas keamanan, dan 3) kemacetan.

Setiap hari Bali menghasilkan 4.281 ton atau 1,5 juta ton sampah per tahun. Mirisnya, sebelas persen dari data itu, sampahnya mengalir ke laut. Sedangkan daerah dengan penghasilan sampah terbanyak ada di Denpasar, Badung dan Gianyar. Dari data tersebut, juga disebut lebih banyak sampah yang tidak dikelola (52 persen) dibanding dengan yang dikelola (48 persen). Permasalahan ini diharapkan mendapat perhatian serius dari semua komponen, baik pemerintah maupun masyarakat. Aturan apapun yang dibuat pemerintah tanpa adanya dukungan masyarakat akan menjadi sia-sia

Bali sebagai daerah tujuan wisata, keindahan alam dan kebersihan lingkungannya merupakan modal utama dalam mempertahankan keberlangsungan pariwisata di Bali. Kebersihan lingkungan menjadi salah satu bagian dari sapta pesona yaitu aman, tertib, bersih, sejuk, indah, ramah dan kenangan, memiliki peran penting dalam menciptakan kenyamanan bagi wisatawan. Bali sebagai destinasi wisata memiliki beragam keindahan alam, biota laut dan hayati serta keunikan budaya. Namun kondisi ini bertolak belakang dengan kenyataan yang ada. Indahnya alam pulau Bali dinodai dengan keberadaan sampah yang tidak dibuang pada tempatnya.

PKM dalam bentuk pengajaran untuk meningkatkan kemampuan Bahasa Inggris dilaksanakan karena melihat permasalahan mitra di Unit Pelaksana Teknik Daerah (UPTD) Tempat Pengelolaan Sampah Dinas Kehutanan dan Lingkungan Hidup (DKLH) Provinsi Bali yang sering mendapat kunjungan dari luar negeri untuk melihat bagaimana pengelolaan sampah. Pentingnya peningkatan kemampuan bahasa Inggris ini bertujuan agar para pegawai di lingkungan UPTD Tempat Pengelolaan Sampah DKLH Provinsi Bali memiliki kompetensi dalam berkomunikasi menggunakan bahasa asing khususnya bahasa Inggris sehingga mampu 
1170 Peningkatan Kemampuan Bahasa Inggris bagi Pegawai UPTD Tempat Pengelolaan Sampah Dinas Kehutanan dan Lingkungan Hidup Provinsi Bali- I Wayan Budiarta, Ni Wayan Kasni, Made Susini DOI: https://doi.org/10.31004/abdidas.v2i5.442

memberikan informasi atau penjelasan terkait dengan sistem pengelolaan sampah. Kemampuan memberikan penjelasan baik kepada tamu yang berkunjung dari luar negeri ini sangat penting untuk menyuarakan atau menginformasikan bahwa dalam hal ini pemerintah dan masyarakat Bali terus berupaya dengan berbagai cara untuk mengatasi permasalahan sampah. Hal ini sangat penting untuk disampaikan sehingga tidak memberikan citra yang buruk bagi keberlanjutan pariwisata di Bali mengingat isu sampah sangat mengganggu citra Bali yang terkenal sebagai daerah tujuan wisata.

PKM ini dilaksanakan dalam bentuk pengajaran bahasa Inggris dengan menggunakan metode pengajaran bahasa yang lebih interaktif dan inovatif. Pengajaran ini difokuskan pada peningkatan kemampuan berbahasa Inggris yang diawali dengan peningkatan perbendaharaan kata yang dimiliki, sehingga lebih mudah untuk menggunakannya dalam komunikasi. Dengan metode ini diharapkan para pegawai merasa lebih tertarik untuk meningkatkan kemampuan berbahasa Inggris mereka dan juga dapat meningkatkan kepercayaan diri mereka ketika berkomunikasi dengan tamu asing. Peningkatan kemampuan bahasa Inggris dan peningkatan keberanian dalam berbicara merupakan modal utama bagi pegawai sehingga mereka mampu memberikan penjelasan atau informasi yang tepat dan benar terkait dengan penangan sampah di Bali yang tentunya berdampak pada citra pariwisata Bali.

Solusi terhadap permasalahan mitra khususnya dengan peningkatan kemampuan bahasa Inggris adalah dalam bentuk pelatihan bahasa Inggris. Dalam pelatihan bahasa Inggris tersebut metode pengajaran bahasa yang digunakan adalah metode pembelajaran bahasa Inggris yang lebih interaktif dan inovatif sehingga efektif meningkatkan kemampuan bahasa Inggris. Dengan metode pembelajaran seperti ini pegawai diharapkan menjadi lebih tertarik untuk belajar bahasa Inggris sehingga berdampak pada peningkatan kemampuan berbahasa Inggris pegawai UPTD Tempat Pengelolaan Sampah DKLH Provinsi Bali. Metode pembelajaran bukanlah satu satunya faktor yang menentukan keberhasilan proses pembelajaran begitu pula dalam proses pembelajaran bahasa. Namun demikian, faktor ini tetap memegang peranan yang sangat penting dalam keberhasilan sebuah proses pembelajaran. Solusi yang diberikan terkait permasalahan mitra yang memiliki kemampuan bahasa Inggris yang masih rendah adalah berupa metode pembejalaran yang interaktif dan inovatif Munby menyebut Pendekatan Komunikatif sebagai 'Communicative Syllabus' (Munby, 1978). Widdowson menyebutnya sebagai 'Communicative Approach' (Widdowson, 1978), sedangkan Richards \& Rogers menyebutnya 'Communicative Language Teaching'

(CLT) (Richards \& and Rogers S. T., 2001). Istilah-istilah seperti Notionol - Functional Approach atau Functional Approach.

Lebih lanjut, Littlewood mengungkapkan bahwa Communicative Language Teaching menurutnya "One of the most characteristic features of communicative language teaching is that it pays systemic attention to functional as well 
1171 Peningkatan Kemampuan Bahasa Inggris bagi Pegawai UPTD Tempat Pengelolaan Sampah Dinas Kehutanan dan Lingkungan Hidup Provinsi Bali- I Wayan Budiarta, Ni Wayan Kasni, Made Susini DOI: https://doi.org/10.31004/abdidas.v2i5.442

as structural aspects of language, combining these into a mor fully communicative view." Artinya bahwa CLT merupakan metode yang berjalan bersamaan antara penguasaan struktur bahasa dan penguasaan komunikasi (Littlewood, 2002). Karena dua hal tersebut tidak dapat dipisahkan dan saling berkaitan untuk menguasai sebuah bahasa khususnya bahasa Inggris. Menurut Richards dan Rodgers ada lima prinsip dalam menggunakan metode Communicative Language Teaching yaitu sebagai berikut: (1) Learners learn a language through using it to communicate. (Pembelajar belajar bahasa dengan menggunakannya untuk berkomunikasi), (2) authentic and meaningful communication should be the goal of classroom activities. (Keontetikan dan Kemaknaan komunikasi menjadi tujuan dari kegiatan yang ada didalam kelas), (3) fluency is an important dimension of communication. (Kelancaran adalah dimensi yang penting di dalam berkomunikasi), (4) communication involves the integration of different language skills. (Komunikasi mencakup integrasi dari empat keterampilan dalam pembelajaran bahasa), (5) learning is a process of creative construction and involves trial and error.

(Belajar adalah sebuah proses konstruksi kreatif dari pada melakukan percobaan dan kesalahan (Richards \& and Rogers S. T., 2001).

Penggunaan metode CLT ditunjukkan sangat bermanfaat dalam pengajaran bahasa Inggris seperti hasil dari studi George M. Jacobs dan Thomas S.C. Farrell pada tahun 2003 dengan judul "Understanding and Implementing the CLT Paradigm" yang menyatakan ada perubahan yang lebih baik pada pengajar bahasa kedua atau bahasa asing yaitu bahasa Inggris dalam proses baik mengajar ataupun belajar (Jacobs \& and Farell, 2003). Kemudian dari hasil studi Ming Chang pada tahun 2011 dengan judul "EFL Teacher's Attitudes toward Communicative Language Teaching in Taiwanese College" dari hasil studinya menunjukkan para pengajar menunjukkan kenyamanan dan keefektifan dalam mengajar bahasa Inggris ketika menggunakan metode CLT dalam pembelajaran (Chang, 2011).

Penerapan metode CLT dalam pembelajaran bahasa Inggris juga dilakukan dalam penelitian yang dilaksanakan oleh Sabrina (2020) yang menunjukkan bahwa pendekatan ini mencakup beberapa aksioma yang bertujuan mengaktifkan siswa untuk dapat berkomunikasi dengan baik dalam bahasa yang dipelajari (Sabrina, 2020). CLT menekankan pada kontekstual dan keasliannya, sehingga siswa dapat mempelajari bahan secara keseluruhan dan dapat dengan mudah menyesuaikannya pengetahuan dengan realitas yang ada.

Berdasarkan uraian di atas dapat disimpulkan bahwa metode ini telah dipakai dalam proses pembelajaran bahasa Inggris dan terbukti efektif dan mampu meningkatkan kemampuan bahasa Inggris secara signifikan dan pembelajar merasa nyaman dengan penerapan metode tersebut. Murujuk hal tersebut, maka sangat tepat menerapkan metode ini untuk menjawab permasalahan mitra dalam hal ini adalah pegawai UPTD Tempat Pengelolaan Sampah DKLH Provinsi Bali. 
1172 Peningkatan Kemampuan Bahasa Inggris bagi Pegawai UPTD Tempat Pengelolaan Sampah Dinas Kehutanan dan Lingkungan Hidup Provinsi Bali- I Wayan Budiarta, Ni Wayan Kasni, Made Susini DOI: https://doi.org/10.31004/abdidas.v2i5.442

\section{METODE}

Metode Solusi dari permasalahan yang dihadapi mitra adalah dalam bentuk metode pembelajaran yang interaktif dan inovatif. Metode pembelajaran yang ditawarkan sebagai solusi ini adalah metode pembelajaran Communicative Language Teaching (CLT). Metode pembelajaran ini merupakan metode yang terbukti efektif dalam bidang pengajaran bahasa sehingga proses pembeljaran dapat berlangsung secara efektif dan efisien. Metode ini dapat memberikan kegiatan yang lebih terpusat pada pembelajar atau Student Center Learning. Selain itu, pada metode ini diterapkan suatu kegiatan yang bisa meningkatkan minat dan motivasi siswa dalam belajar.

Communicative Language Teaching (CLT) adalah sebuah pendekatan dalam pengajaran bahasa asing yang lebih menekankan konsep interaksi, baik dalam proses maupun tujuan dari proses pembelajaran tersebut. Secara historis, CLT ini muncul sebagai respon terhadap Metode Audio-Lingual (ALM), yang dianggap tidak tepat dalam pembelajaran bahasa. Metode ini berangkat dari paham bahwa bahasa adalah suatu alat untuk berkomunikasi bukan sekedar seperangkat aturan. Oleh karena itu, pengajaran bahasa seharusnya berpegang teguh pada pemahaman tersebut, yaitu belajar bahasa adalah belajar menggunakan bahasa bukan mempelajari tentang bahasa tersebut.

Karakteristik utama dari CLT adalah adanya kombinasi antara aspek-aspek bahasa secara fungsional dan struktural. Secara fungsional, CLT menekankan pada bagaimana bahasa tersebut digunakan, sedangkan secara struktural, CLT, menekankan pada sistem atau aturan bahasa. Meskipun begitu, dalam aplikasinya porsi fungsional lebih besar daripada porsi struktural karena pengajaran-pengajaran tentang aturan bahasa tidak diberikan secara langsung, melainkan tersirat dalam proses belajar. Mengacu pada pendekatan komunikatif, agar proses pembelajaran dapat berlangsung harus ditekankan pada pentingnya 3 variabel, yaitu komunikasi, tugas, makna. Komunikasi merupakan kegiatan yang melibatkan komunikasi nyata untuk mempromosikan pembelajaran. Tugas merupakan kegiatan di mana bahasa digunakan untuk melaksanakan tugas-tugas yang bermakna dan mendukung proses pembelajaran. Sementara makna bermakna bahwa bahasa memiliki makna dan otentik untuk meningkatkan motivasi siswa dalam belajar.

Jika dicermati lebih jauh, CLT memiliki beberapa tujuan yang ingin dicapai meliputi (1) pembelajar dapat menggunakan bahasa sebagai alat untuk berkomunikasi. (2) pembelajar dapat menggunakan bahasa sebagai alat untuk mengekspresikan sesuatu, (3) dan pembelajar dapat menggunakan ekspresi-ekspresi bahasa dengan tepat ketika berkomunikasi. Dalam pengaplikasiannya di dalam kelas, CLT menggunakan setiap kegiatan yang melibatkan interaksi autentik, baik antara pengajar dan pembelajar maupun antara pembelajar itu sendiri. Ada dua bentuk kegiatan dalam kelas CLT, yaitu kegiatan komunikasi fungsional yang bertujuan untuk mengembangkan kemampuan (skill) dan fungsi bahasa tertentu, tetapi tetap melibatkan komunikasi dan kegiatan interaksi sosial yang 
1173 Peningkatan Kemampuan Bahasa Inggris bagi Pegawai UPTD Tempat Pengelolaan Sampah Dinas Kehutanan dan Lingkungan Hidup Provinsi Bali- I Wayan Budiarta, Ni Wayan Kasni, Made Susini DOI: https://doi.org/10.31004/abdidas.v2i5.442

menekankan pada penggunaan bahasa tersebut, seperti percakapan dan diskusi, dialog, bermain peran (role play), interviews, information gap, games, dan bentuk lainnya: menguraikan cara yang digunakan untuk menyelesaikan masalah. Contoh metode: a) pendidikan masyarakat, misalnya penyuluhan yang bertujuan meningkatkan pemahaman serta kesadaran, b) difusi ipteks, misalnya kegiatan yang menghasilkan produk bagi kelompok sasaran, c) pelatihan, misalnya kegiatan yang disertai dengan demonstrasi atau percontohan untuk menghasilkan keterampilan tertentu, d) mediasi, misalnya kegiatan yang menunjukkan pelaksana PKM sebagai mediator dalam menyelesaikan masalah yang ada dalam masyarakat, e) advokasi, misalnya kegiatan yang berupa pendampingan terhadap kelompok sasaran.

\section{HASIL DAN PEMBAHASAN}

Pelatihan bahasa Inggris ini dilaksanakan selama 8 kali pertemuan/pelatihan Pertemuan pertama berlangsung pada hari Selasa tanggal 20 April 2021, yang kedua berlangsung pada hari Selasa tanggal 27 April 2021, yang ketiga dilaksanakan hari Selasa tanggal 4 Mei 2021, yang keempat dilaksanakan hari Selasa tanggal $11 \mathrm{Mei}$ 2021, yang kelima berlangsung pada hari Selasa 18 Mei 2021, yang keenam tanggal 22 Mei 2021, yang ketujuh berlangsung hari Selasa tanggal 4 Juni 2021, dan yang terakhir dilaksanakan hari Selasa tanggal 22 Juni 2021.

Pada pertemuan pertama diberikan pretest kepada peserta pelatihan untuk mengukur sejauh mana kemampuan berbicara bahasa Inggris. Instruktur meminta kepada seluruh peserta untuk memperkenalkan diri dengan menggunakan bahasa Inggris kemudian instruktur melanjutkan melakukan tanya jawab menggunakan kepada peserta dengan fokus pada pertanyaan yang menggunakan WH Question. Setelah itu instruktur melanjutkan dengan memberikan materi Introducing yourself and Other dan juga dilanjutkan tentang WH Question.

Materi pertemuan kedua adalah Describing $J o b$. Pelatihan diawali dengan pemberian Ice Breaker kepada peserta. Peserta diminta bermain "Find someone who" Masing-masing peserta harus mencari nama teman-temannya yang melakukan aktivitas tertentu, contoh: Find someone who loves dog". Setelah siswa menemukannya, mereka langsung menulis nama temannya di kertas. Kemudian kegiatan utama mahasiswa berlatih beberapa language expression seperti: (1) How would you greet when people come at 10 am? (2) What would you say when you meet people for the first time? (3) How do you escort a guest? (4) If you don't know name of a person, how do you call the person's name? (5) How to ask name politely? (6) How to ask someone where they come from? (7) How to introduce yourself as a staff in your office? (8) How to offer coffeel tea? (9) How to explain your office area? dan (10) How to ask someone to repeat what they say? Kemudian kegiatan pelatihan ditutup dengan meminta membuat percakapan bersama temannya kemudian mempraktikkan percakapan tersebut dan instruktur memberikan feedback terkait praktik yang telah dilakukan peserta.

Materi pertemuan ketiga adalah Describing Job yang diawali dengan Ice Breaker. Kelas dibagi 
1174 Peningkatan Kemampuan Bahasa Inggris bagi Pegawai UPTD Tempat Pengelolaan Sampah Dinas Kehutanan dan Lingkungan Hidup Provinsi Bali- I Wayan Budiarta, Ni Wayan Kasni, Made Susini DOI: https://doi.org/10.31004/abdidas.v2i5.442

menjadi dua grup dan masing -masing siswa di grup 1 membawa nama ruangan di kantor. Masingmasing peserta di grup 2 membawa penjelasan masing-masing ruangan di kantor. Peserta diminta untuk menemukan nama ruangan dan penjelasannya, seperti Car Park ---You can park your car here, Corridor---It's a long narrow passage, Reception --- you can ask information here, Canteen --- You can get something to eat, Stairs - The way to get to the next floor, Meeting room - a place to hold a conference, Bulletin board--- a place to put up an announcement. Untuk kegiatan utama instruktur meminta peserta untuk bertanya dengan menggunakan language expression Where's the ...? It's ... Where are the ....? They're ...How many ...? There are ...Next to.../ behind.../ near.../ in front of .../ at the front of .../ far from .../ on the left.../ to the left of .... Kegiatan penutup adalah masing-masing grup diminta untuk peserta membuat sketsa kantor lalu menukarkannya dengan sketsa grup lain. Kemudian, masing-masing grup berlatih bertanya dan menjawab cara menjelaskan denah kantor.

Pada pertemuan keempat materinya adalah Describing Public Places seperti biasa Ice Breaker dengan memberikan peserta bermain dengan menggunakan ungkapam "What place am I?". Peserta kemudian diberikan kertas yang berisi public places dengan memberikan petunjuk (clue) selanjutnya peserta lain mencoba untuk menebaknya. Beberapa tempat umum yang diberikan, seperti Cafe / Train Station / Sport Center / Bank/ Library / Post office / Mall / Swimming pool / Temple / Supermarket / Cinema. Kegiatan utama pelatihan dilanjutkan dengan instruktur menunjukkan peta sederhana, kemudian instruktur menjelaskan istilah Turn right/ Turn left/ Go along the / Go pass the / Until the end of the street/ Excuse me, how can I get to the cinema? Kegiatan pelatihan ditutup dengan meminta peserta untuk melakukan latihan secara berpasangan berlatih dengan mempergunakan ungkapan-ungkapan di atas secara bergantian dengan berbekal peta yang telah diberikan. Di akhir pelatihan instruktur memberikan feedback terhadap apa yang telah dilakukan oleh peserta terhadap lima (5) aspek yang mencakup lima (5) aspek dalam speaking, yaitu pengucapan, tata bahasa, kosa kata, kelancaran dan pemahaman.
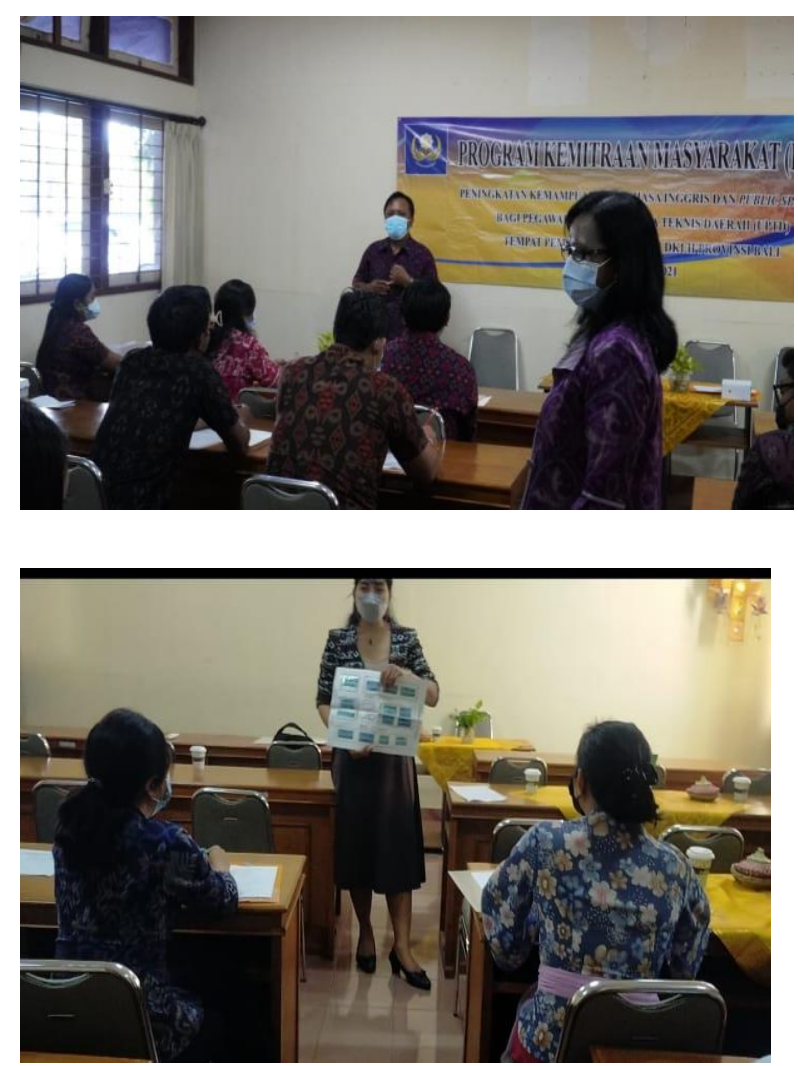

Gambar 2. Penyampaian Materi oleh Instruktur

Materi pertemuan kelima membahas tentang Telling Experience. Diawal pertemuan peserta diberikan kesempatan untuk bermain 'Tell $M e$ ' 
1175 Peningkatan Kemampuan Bahasa Inggris bagi Pegawai UPTD Tempat Pengelolaan Sampah Dinas Kehutanan dan Lingkungan Hidup Provinsi Bali- I Wayan Budiarta, Ni Wayan Kasni, Made Susini DOI: https://doi.org/10.31004/abdidas.v2i5.442

Masing-masing peserta diberikan kertas yang berisikan hal-hal yang mereka lakukan sebelumnya, kemudian peserta diminta untuk bertanya kepada pasangannya dengan menggunakan ungkapan seperti What is your best experience? What did you do this morning? What is your dream holiday? What is your motivation to learn English? dan What is your unforgettable holiday? Game yang diberikan ini menitikberatkan pada penggunaan simple past tense dengan fokus pada penggunaan bentuk lampau dari verba. Setelah itu, instruktur menjelaskan penggunaan ungkapan yang digunakan untuk bertanya terkait dengan past event seperti, bentuk past dari verba seperti What did you do ...? / Where were you ...? / Who were you with ..?/ Did you ...? Di samping itu instruktur juga memberikan contoh cara menceritakan pengalaman secara detail dengan menggunakan mind mapping $5 \mathrm{~W} 1 \mathrm{H}+$ perasaan mereka. Sebagai penutup pelatihan instruktur meminta masing-masing peserta untuk menulis pengalaman berkesan mereka kemudian menceritakannya di depan kelas dan peserta lain diberikan kesempatan untuk bertanya sehingga memotivasi peserta lain untuk berani berbicara. Setelah itu instruktur akan memberikan feedback terhadap apa yang sudah dilakukan oleh seluruh peserta terkait pengucapan, tata bahasa, kosa kata, kelancaran dan pemahaman.

Pertemuan keenam diawali dengan memberikan Ice Breaking berupa pertanyaan kepada peserta terkaut dengan hal hal yang merupakan bagian dari $\mathrm{CV}$ dengan menggunakan WH Question. Hal ini diberikan untuk menggiring peserta bahwa topik pelatihan hari ini terkait dengan asking dan telling CV dari para paserta. Kemudian peserta diminta untuk bertanya kepada peserta yang lain terkait dengan CV. Mereka secara bergantian saling bertanya dan menjawab. Kegiatan utama dilanjutkan dengan instruktur menjelaskan terkait ungkapan-ungkapan yang digunakan dalam hal bertanya dan menjawab terkait dengna CV. Sebagai akhiri dari kegiatan pelatihan peserta diminta mempraktikkan asking and telling CV yang kemudian diberikan feedback oleh instruktur sebagai bahan evaluasi atas apa yang telah dilakukan atau dipraktikkan peserta dalam hal lima (5) aspek dalam speaking yang meliputi pengucapan, tata bahasa, kosa kata, kelancaran, dan pemahaman.

Materi pertemuan ketujuh adalah tentang Describing Job. Diawali dengan Ice breaker dengan cara setiap peserta diberikan satu kertas yang berisi pekerjaan, kemudian peserta yang lain yang menjadi pasangannya diminta untuk menebak dengan cara bertanya secara bergiliran seperti $D o$ you work indoor/ outdoor? Do you wear uniform? Do you work part time? Is it risky? Do you use special equipment? Do you work on a computer dan lain sebagainya. Kemudian kegiatan pelatihan dilanjutkan Instruktur dengan menjelaskan penggunaan do you...? Does she..? Instruktur juga menjelaskan tentang beberapa jenis pekerjaan sehingga menambah perbendaharaan kata dari peserta. Pertemuan ini ditutup dengan kegiatan di mana masing-masing peserta diminta untuk menjelaskan pekerjaannya/ keluarga/ pekerjaan temannya di depan kelas. Dan kemudian diakhiri dengan pemberian feedback oleh instruktur 
1176 Peningkatan Kemampuan Bahasa Inggris bagi Pegawai UPTD Tempat Pengelolaan Sampah Dinas Kehutanan dan Lingkungan Hidup Provinsi Bali- I Wayan Budiarta, Ni Wayan Kasni, Made Susini DOI: https://doi.org/10.31004/abdidas.v2i5.442

Materi pertemuan kedelapan ini adalah masih terkait dengan telling job or duties. Sebagai Ice Breaker, peserta diberikan permainan terkait matching games. Setiap peserta diberikan 5 lembar kertas kecil yang berisikan tentang job vocabularies kemudian setiap peserta diminta untuk menemukan deskripsi masing-masing job vocabularies dengan mencari deskripsi di dalam kertas yang telah ditaruh secara acak di atas meja. Setelah itu instruktur memberikan baik dalam bentuk kalimat positif, negatif, dan interrogatif terkait cara menceritakan tentang job description. Pertemuan kedelapan ditutup dengan memberikan post-test kepada seluruh peserta untuk melihat sejauh mana peningkatan kemampuan bahasa Inggris dengan menggunakan metode CLT.

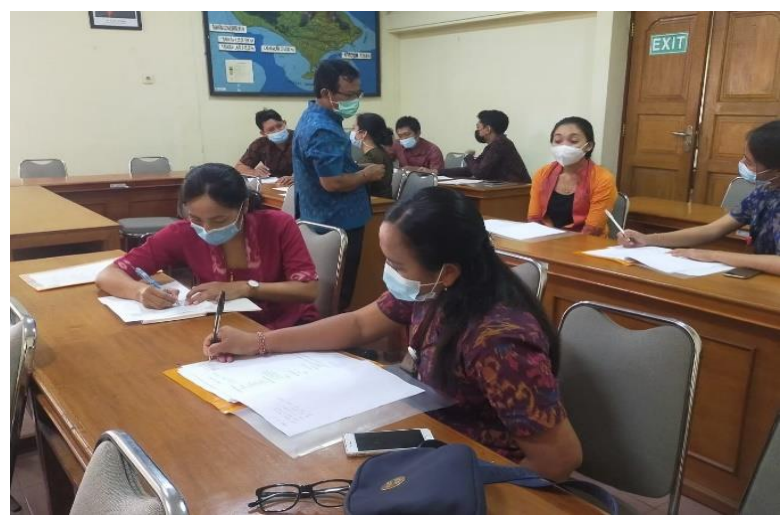

Gambar 2. Aktivitas Belajar Peserta dalam Pelatihan Bahasa Inggris

Seperti telah diuraikan di atas bahwa di pertemuan awal peserta diberikan pretest untuk melihat kemampuan peserta sebelum dilaksanakannya pelatihan. Tabel 1 berikut menyajikan hasil pretest tersebut.

Tabel 1. Hasil Pretest

\begin{tabular}{|c|l|c|c|c|c|c|c|}
\hline \multirow{2}{*}{ NO } & \multirow{2}{*}{$\begin{array}{c}\text { KODE } \\
\text { PESERTA }\end{array}$} & \multicolumn{7}{|c|}{ HASIL PENILAIAN 5 ASPEK SPEAKING } & \multirow{2}{*}{ Rerata } \\
\cline { 3 - 7 } & & Pengucapan & $\begin{array}{c}\text { Tata } \\
\text { Bahasa }\end{array}$ & $\begin{array}{c}\text { Kosa } \\
\text { Kata }\end{array}$ & Kelancaran & Pemahaman & \\
\hline 1 & P1 & 3 & 3 & 3 & 3 & 3 & 3 \\
\hline 2 & P2 & 2 & 2 & 3 & 3 & 2 & 2,4 \\
\hline 3 & P3 & 3 & 2 & 2 & 3 & 2 & 2,4 \\
\hline 4 & P4 & 3 & 3 & 3 & 2 & 2 & 2,6 \\
\hline 5 & P5 & 2 & 2 & 3 & 2 & 2 & 2,2 \\
\hline 6 & P6 & 3 & 2 & 3 & 3 & 3 & 2,8 \\
\hline 7 & P7 & 3 & 3 & 3 & 2 & 2 & 2,8 \\
\hline 8 & P8 & 2 & 3 & 2 & 2 & 2,4 \\
\hline 9 & P9 & 3 & 2 & 3 & 2 & 2 & 2,2 \\
\hline 10 & P10 & 2 & 2 & 3 & 2 & 2 & 2,6 \\
\hline 11 & P11 & 3 & 2 & 3 & 3 & 3 & 2,4 \\
\hline 12 & P12 & 3 & 2 & 3 & 2 & 3 & 2,6 \\
\hline 13 & P13 & 2 & 2 & 3 & 2 & 2 & 2,2 \\
\hline 14 & P14 & 3 & 2 & 3 & 3 & 3 & 2,8 \\
\hline 15 & P15 & 3 & & & & 2,55 \\
\hline RERATA
\end{tabular}

Jika merujuk data pada tabel 1 di atas dapat disimpulkan bahwa rerata hasil pretest terhadap tingkat kemampuan bahasa Inggris (speaking) mencapai 2,55 dengan rentang skor 1-5. Skor ini menunjukkan bahwa kemampuan bahasa Inggris para pegawai di lingkungan UPTD Tempat 
1177 Peningkatan Kemampuan Bahasa Inggris bagi Pegawai UPTD Tempat Pengelolaan Sampah Dinas Kehutanan dan Lingkungan Hidup Provinsi Bali- I Wayan Budiarta, Ni Wayan Kasni, Made Susini DOI: https://doi.org/10.31004/abdidas.v2i5.442

Pengelolaan Sampah DKLH Provinsi Bali perlu ditingkatkan lagi. Setelah dilaksanakan pelatihan selama delapan kali pertemuan, hasil post-test menunjukkan adanya peningkatan kemampuan seperti yang disajikan pada tabel 2 berikut.

Tabel 2. Hasil Post-test

\begin{tabular}{|c|c|c|c|c|c|c|c|}
\hline \multirow{2}{*}{ NO } & \multirow[b]{2}{*}{$\begin{array}{c}\text { KODE } \\
\text { PESERTA }\end{array}$} & \multicolumn{5}{|c|}{ HASIL PENILAIAN 5 ASPEK SPEAKING } & \multirow[b]{2}{*}{ Rerata } \\
\hline & & Pengucapan & $\begin{array}{c}\text { Tata } \\
\text { Bahasa }\end{array}$ & $\begin{array}{l}\text { Kosa } \\
\text { Kata }\end{array}$ & Kelancaran & Pemahaman & \\
\hline 1 & $\mathrm{P} 1$ & 5 & 4 & 5 & 5 & 4 & 4,6 \\
\hline 2 & $\mathrm{P} 2$ & 4 & 3 & 4 & 4 & 4 & 3,8 \\
\hline 3 & P3 & 4 & 3 & 5 & 4 & 4 & 4 \\
\hline 4 & P4 & 5 & 3 & 5 & 4 & 4 & 4 \\
\hline 5 & P5 & 4 & 3 & 5 & 4 & 4 & 4 \\
\hline 6 & P6 & 4 & 4 & 4 & 4 & 4 & 4 \\
\hline 7 & P7 & 5 & 4 & 5 & 3 & 4 & 4,2 \\
\hline 8 & P8 & 4 & 3 & 5 & 4 & 4 & 4 \\
\hline 9 & P9 & 5 & 3 & 5 & 4 & 4 & 4,2 \\
\hline 10 & P10 & 4 & 3 & 4 & 4 & 4 & 3,8 \\
\hline 11 & P11 & 5 & 3 & 4 & 4 & 4 & 4 \\
\hline 12 & P12 & 4 & 4 & 5 & 4 & 4 & 4,2 \\
\hline 13 & P13 & 4 & 4 & 4 & 3 & 4 & 3,6 \\
\hline 14 & P14 & 4 & 4 & 5 & 4 & 4 & 4,2 \\
\hline 15 & P15 & 5 & 4 & 4 & 4 & 4 & 4,2 \\
\hline \multicolumn{7}{|c|}{ RERATA } & 4,05 \\
\hline
\end{tabular}

Merujuk data pada tabel 2 di atas dapat disimpulkan bahwa rerata hasil post-test terhadap tingkat kemampuan bahasa Inggris yang mencapai 4.05 dengan rentang skor 1-5. Merujuk hasil posttest tersebut, maka terjadi peningkatan skor yang bermakna bahwa pelatihan tersebut mampu meningkatkan kemampuan berbahasa Inggris pegawai di lingkungan UPTD Tempat Pengelolaan Sampah DKLH Provinsi Bali sehingga kegiatan PKM ini dapat dikatakan memiliki manfaat dalam hal menjawab atau memberikan solusi terhadap permasalahan mitra dan ini sekaligus menunjukkan bahwa kegiatan PKM ini telah berhasil dilaksanakan dengan baik.

\section{UCAPAN TERIMA KASIH}

Ucapan terima kasih ditujukan kepada Rektor Universitas Warmadewa, Prof. dr. Dewa Putu Widjana, DAP\&E., Sp. ParK atas hibah Pengabdian kepada Masyarakat Tahun 2021 dan kepada Dr. Drs. I Wayan Wesna, Astara, SH., M.Hum. MH. selaku Kepala Lembaga Pengabdian Masyarakat Universitas Warmadewa atas kesempatan yang diberikan dalam melaksanakan kegiatan PKM ini. Ucapan terima kasih ditujukan kepada Kepala UPTD Pengelolaan Sampah Dinah Kehutanan dan Lingkungan Hidup Provinsi Bali, Dr. Ni Made Armadi SP., M.Si atas kerjasama dan batuannya sehingga PKM ini dapat terlaksana dengan baik dan lancar. 
1178 Peningkatan Kemampuan Bahasa Inggris bagi Pegawai UPTD Tempat Pengelolaan Sampah Dinas Kehutanan dan Lingkungan Hidup Provinsi Bali- I Wayan Budiarta, Ni Wayan Kasni, Made Susini DOI: https://doi.org/10.31004/abdidas.v2i5.442

\section{SIMPULAN}

Merujuk pada pelaksanaan PKM dalam bentuk pelatihan bahasa Inggris bagi pegawai di lingkungan UPTD Tempat Pengelolaan Sampah DKLH Provinsi Bali dapat disimpulkan bahwa kegiatan ini telah berjalan dengan lancar dan sukses sesuai dengan rencana kegiatan yang tertuang dalam proposal kegiatan. PKM dalam bentuk pelatihan bahasa Inggris ini telah dilaksanakan selama delapan (8) kali pertemuan/pelatihan yang diawali pada tanggal 20 April 2021 dan berakhir pada tanggal 22 Juni 2021. Pelaksanaan PKM telah mampu memberikan solusi terhadap permasalahan mitra. Hal ini dapat dilihat pada hasil pelatihan yang menunjukkan tejadinya peningkatan kemampuan bahasa Inggris peserta yang awalnya berada dikisaran 2,55 (pretest) meningkat menjadi 4,05 (post-test) dengan rentang skor 1-5. Ini membuktikan bahwa pelatihan bahasa Inggris yang diberikan kepada peserta telah mampu secara signifikan meningkatkan kemampuan berbahasa Inggrisnya. Di samping itu hasil post-test juga menunjukkan bahwa variasi kemampuan berbahasa Inggris antar peserta tidak memiliki perbedaan yang sangat jauh.

\section{DAFTAR PUSTAKA}

Chang, M. (2011). EFL Teachers' Attitudes toward Communicative Language Teaching in Taiwanese College. Asian EFL Journal Professional Teaching Articles, 53, 17-34. http://www.asian-efljournal.com/PTA/Volume-53-mc.pdf

Jacobs, G. M., \& and Farell, T. S. C. (2003). Understanding and Implementing the CLT (Communicative Language Teaching) Paradigm. RELC Journal, 34, 2-30. https://journals.sagepub.com/doi/10.1177/003

\section{2}

Littlewood, W. (2002). Communicative Language Teaching. Cambridge University Press.

Munby, J. (1978). Communicative Syllabus Design. Cambridge University Press.

Richards, J. C., \& and Rogers S. T. (2001). Approaches and Methods in Language Teaching (Second). Cambridge University Press.

Sabrina, A. (2020). The Implementation of Communicative Language Teaching in English Practice. Notion: Journal of Linguistics, Literature, and Culture, 2(1), 17-27. http://journal2.uad.ac.id/index.php/notion/arti cle/view/1750/pdf

Widdowson, H. G. (1978). Teaching Language as Communication. Oxford University Press.

Brown, Douglas. H. (2003). Language Assessment, Principle and Classroom Practice. San Fransisco, USA: Prentice Hall Inc.

Buttmer, Amy. (2013). Aktivitas Permainan dan Strategi Penilaian untuk Kelas Bahasa Asing. Jakarta: PT Indeks.

Chang, Ming. (2011). EFL Teachers' Attitudes toward Communicative Language Teaching in Taiwanese College. Asian EFL Journal Professional Teaching Articles, 53, 17-34. Retrieved from http://www.asian-efljournal.com/PTA/Volume-53-mc.pdf

Djamarah, Syaiful Bachri. (1996). Strategi Belajar Mengajar. Jakarta: Rineka Cipta.

Jacobs, G.M. dan Farell, T.S.C. Understanding and Implementing the CLT (Communicative Language Teaching) Paradigm. RELC Journal. Vol.34. 5-30. Retrieved from https://journals.sagepub.com/doi/10.1177/00 3368820303400102

Littlewood, William. 2002. Communicative Language Teaching. Cambridge: Cambridge University Press.

Richards, Jack C., and Theodore S. Rodgers. 2001. Approaches and Methods in Language 
1179 Peningkatan Kemampuan Bahasa Inggris bagi Pegawai UPTD Tempat Pengelolaan Sampah Dinas Kehutanan dan Lingkungan Hidup Provinsi Bali- I Wayan Budiarta, Ni Wayan Kasni, Made Susini DOI: https://doi.org/10.31004/abdidas.v2i5.442

Teaching. Second Edition. Cambridge: Cambridge University Press.

Sabrina, Arini. (2020). The Implementation of Communicative Language Teaching in English Practice. Notion: Journal of Linguistics, Literature, and Culture Vol 2 (1). 17-27. Retrieved from http://journal2.uad.ac.id/index.php/notion/arti $\underline{\text { cle/view/1750/pdf }}$ 